\title{
Hydrogen-rich saline may be an effective and specific novel treatment for osteoradionecrosis of the jaw
}

This article was published in the following Dove Press journal:

Therapeutics and Clinical Risk Management

14 October 2015

Number of times this article has been viewed

\section{Yuanli Chen \\ Chunlin Zong \\ Yuxuan Guo \\ Lei Tian}

Department of Cranio-facial Trauma and Orthognathic Surgery Laboratory of Military Stomatology, School of Stomatology, The Fourth Military Medical University, Shaanxi Key Laboratory of Stomatology, Xi'an, People's Republic of China
Correspondence: Lei Tian School of Stomatology, The Fourth Military Medical University, 145 West Changle Road, Xi'an, 7I0032, People's Republic of China

Tel +862984776109

Fax +86298477 6097

Email tianleison@163.com

\begin{abstract}
Hydrogen, a therapeutic medical gas, can exert antioxidant activity via selectively reducing cytotoxic reactive oxygen species such as hydroxyl radicals. Hydrogen-rich saline is an alternative form of molecular hydrogen that has been widely used in many studies, including metabolic syndrome, cerebral, hepatic, myocardial ischemia/reperfusion, and liver injuries with obstructive jaundice, with beneficial results. Osteoradionecrosis of the jaw is a serious complication following radiotherapy for head and neck cancers. It has long been known that most radiation-induced symptoms are caused by free radicals generated by radiolysis of $\mathrm{H}_{2} \mathrm{O}$, and the hydroxyl radical is the most reactive of these. Reducing the hydroxyl radical can distinctly improve the protection of cells from radiation damage. We hypothesized that hydrogen-rich saline might be an effective and specific method of managing and preventing osteoradionecrosis of the jaw.
\end{abstract}

Keywords: osteoradionecrosis, hydrogen, reactive oxygen species

\section{Introduction}

Hydrogen is one of the simplest chemical elements, forming approximately $75 \%$ of the elemental mass of the universe. It is a colorless, tasteless, odorless, non-irritating, and highly flammable diatomic gas which has been used mainly in fossil fuel processing and ammonia production. ${ }^{1}$ A series of recently published studies have demonstrated that hydrogen can selectively reduce hydroxyl radicals ( $\mathrm{OH}-)$ and peroxynitrite (ONOO-) and exhibit therapeutic antioxidant and anti-apoptotic activities., ${ }^{2,3}$ These studies indicated that molecular hydrogen has a special role as a therapeutic gas by specifically targeting intracellular sources of reactive oxygen species (ROS), but not superoxide and hydrogen peroxide, which play physiological roles.

Subsequent research has demonstrated that a burst of ROS and reactive nitrogen species, such as OH-, superoxide anion, hydrogen dioxide, nitric oxide, and ONOO-, plays a critical role in cell damage after stroke, transplantation injury, myocardial ischemia-reperfusion injury, and other diseases. The study by Ohsawa et $\mathrm{al}^{2}$ was significant in finding that hydrogen might be a gaseous oxygen radical scavenger. This finding aroused the attention of scholars immediately after it was published, and hydrogen's ability to prevent and cure many diseases was discovered subsequently. A diverse range of disorders and organ systems have been targeted, including ischemia-reperfusion injury in the brain, liver, myocardium, intestine, retina, and kidney; Parkinson's disease, oxidative stress-induced cognitive decline, inflammatory disease related to oxidative stress, and metabolic syndrome..$^{2,4-16}$ These diseases have a common feature, oxidative stress, which is generally associated with ROS. As diatomic hydrogen can selectively 
reduce ROS and exert antioxidant activity, hydrogen could be effective in managing and preventing these kinds of diseases.

Osteoradionecrosis of the jaw (ORNJ), which was first described by Regaud in 1922, ${ }^{17}$ is a notorious chronic sequela with devitalization and devascularization of bone due to irradiation, and is basically irreversible and difficult to treat. ${ }^{18}$ It is usually asymptomatic initially, but with the development of lesions patients present with various symptoms, including intractable pain, dysesthesia, halitosis, dysgeusia, and exposed sequestra. In the late stage patients often present with fistula from the oral mucosa or skin, complete devitalization of bone, pathological fractures, and even life-threatening complications. Numerous treatment strategies for this chronic injury have been explored, and as yet no one treatment has been universally accepted. A new theory suggesting a fibroatrophic mechanism regards ORNJ as a radiation-induced fibrotic disease, ${ }^{19,20}$ suggesting that cells in the irradiated region are damaged by acute inflammation accompanied by free radical formation. Although the actual mechanism behind the pathogenesis of ORNJ is not yet fully understood, it has been shown that radiation therapy may cause chronic oxidative stress in irradiated tissues and produce a burst of ROS, thereby inducing the activation of some transcription factors, proinflammatory molecules, and cytotoxicity, leading to chronic inflammation, organ dysfunction, fibrosis, and necrosis. ${ }^{21,22}$ After radiotherapy, ionizing radiation interacts with water molecules in biological systems, thereby inducing a variety of active free radicals, which are capable of causing cellular damage and even death; about $60 \%-70 \%$ of the radiationinduced cellular damage is caused by $\mathrm{OH}-.{ }^{23} \mathrm{OH}$ - can trigger the oxidation of lipids, amino acids, and saccharides, leading to the formation of various secondary free radicals. ${ }^{24-26}$ The effects of free radical scavengers in ameliorating the oxidative injuries caused by radiation have frequently been reported. ${ }^{27,28}$ Therefore, the timely elimination of radiation-induced $\mathrm{OH}$ - should protect normal tissues from radiation injury. This theory has led to a new therapeutic method using drugs that scavenge ROS. ${ }^{29}$ Some researchers have already presented dramatic results in the treatment of ORNJ using anti-fibrosis drugs such as pentoxifylline and tocopherol. ${ }^{30,31}$

\section{Hypothesis}

Our hypothesis was that hydrogen-rich saline may be a promising, effective, and specific treatment for ORNJ, based on the following. Hydrogen, a new medical gas, could potentially selectively reduce $\mathrm{OH}-$ and $\mathrm{ONOO}-$, exerting organ-protective effects through regulating oxidative stress and inflammation. ${ }^{2,3,32}$ It is so mild that it does not disturb metabolic oxidation-reduction reactions or disrupt the ROS involved in cell signaling. ${ }^{2,33}$ However, hydrogen is not convenient for use in patients, and may be dangerous because of its inflammable and explosive nature, but if dissolved in normal saline or pure water, it will be different. The primary advantage of hydrogen-rich saline is that it is portable, easily administered, and safe, with similar antioxidant effects. ${ }^{34}$ In fact, hydrogen water is already sold as a commodity in the market. It is physiologically safe at a correct dose because hydrogen is continuously produced by colonic bacteria in the body and circulates normally in the bloodstream. ${ }^{33}$ Also, the tissue compatibility of hydrogen is greater than that of many other antioxidants because it is an endogenous substance. ${ }^{35}$ Furthermore, hydrogen can also penetrate biomembranes and diffuse into the cytosol, mitochondria, and nuclei, thereby protecting nuclear DNA and mitochondria, suggesting that it could reduce the risk of lifestyle-related diseases and cancer. Last but not least, its relative concentration is quite high, and so it can react with low-density toxic ROS.

\section{Evaluation of the hypothesis}

ORNJ is one of the most severe complications following radiotherapy; it is a radiation-induced bone and soft tissue necrosis that occurs without metastases or the recurrence of a primary cancer. ${ }^{36}$ The prevalence of ORN varies widely from $5 \%$ to $15 \%$ and is most frequently seen $(>70 \%)$ in the first 3 years after radiotherapy. ${ }^{37,38}$ Radiation-induced fibrosis is a new theory of ORNJ that accounts for injuries to normal tissues and bone after radiotherapy. ${ }^{29}$ Based on our current understanding of the pathophysiology of ORN, new protocols could be developed for its prevention and treatment. After radiotherapy the endothelial cells are injured, both directly by radiation and indirectly by free radicals. Injured cells produce chemotactic cytokines that trigger an acute inflammatory response and then generate a further release of ROS from polymorphonuclear cells and macrophages stimulated by the degradation of collagen. ${ }^{39,40}$

According to Ohsawa et al's research, hydrogen can selectively reduce $\mathrm{OH}$ - and ONOO- radicals. ${ }^{2}$ Qian et $\mathrm{al}^{41}$ also demonstrated that hydrogen has radioprotective effects both in vitro and in vivo through the antioxidant pathway. 
Table I Comparison of hydrogen and hydrogen-rich saline

\begin{tabular}{|c|c|c|}
\hline & Hydrogen & Hydrogen-rich saline \\
\hline Explosiveness & High & Low \\
\hline Convenience of application & Requires a sealed chamber or mask in hospital & Easy to use anywhere \\
\hline Portability & Poor & Good \\
\hline Administration route & Inhalation & $\begin{array}{l}\text { Oral ingestion, peritoneal injection, } \\
\text { intravenous injection }\end{array}$ \\
\hline Safety & Poor & Good \\
\hline Limit of concentration & High (because of its explosiveness) & Low \\
\hline Effectiveness & Yes & Yes \\
\hline
\end{tabular}

Although ORNJ is a local lesion, usually accompanied by wound infection and vascular structural damage, ROS, especially $\mathrm{OH}-$ and $\mathrm{ONOO}-$, mediate the main biological effects of ionizing radiation and play a major role in the initiation and progression of pathological damage in ORNJ. ${ }^{21-23}$ Therefore, we deduce that hydrogen could also have a protective role against the detrimental effects of ORNJ. However, because of its safety and convenience, hydrogenrich saline is more suitable for clinical use (Table 1) and has been widely applied in research into ischemia-reperfusion injury and inflammation. The study by Nagata et a ${ }^{12}$ reported that the consumption of hydrogen-saturated water could be safe and effective, and many previous experiments have demonstrated its effects in metabolic syndrome, cerebral, renal, intestinal, and myocardial ischemia-reperfusion injury, and liver injury with obstructive jaundice. ${ }^{7,10,16,42,43}$ Hydrogen-rich saline could be administered by peritoneal injection, intravenously or orally, and each route has its advantages. When ingested orally, hydrogen can be detected in the blood, indicating that it is incorporated into the body. ${ }^{12,44}$ In addition, it diffuses rapidly into cells and a high level of efficacy can be expected. ${ }^{2,5}$ In animal experiments, hydrogen-rich saline administered orally ad libitum throughout the experimental period has been shown to be effective; ${ }^{12,45}$ and its effectiveness was observed in patients after consuming $900 \mathrm{mg} /$ day of hydrogen-rich saline orally for 8 weeks. ${ }^{46}$ Above all, hydrogen-rich saline is easy to drink daily and would be simple to administer without complicating or changing the subject's lifestyle. Despite these advantages of gastric administration, there are some drawbacks to this route of administration. Hydrogen might be lost in the stomach or intestine, as it tends to evaporate in water, and it is difficult to control its concentration and absorption. Peritoneal injection avoids this problem and is widely used in animal experiments. ${ }^{42}$ Although it is still hard to say how much hydrogen gas may remain after intraperitoneal injection, hydrogen concentrations in tissue can be measured using a needle-type sensor, ${ }^{6}$ and it has been shown in many studies that hydrogen at $5 \mathrm{~mL} / \mathrm{kg}$ is really beneficial. ${ }^{4,7,47}$

All of this evidence makes hydrogen-rich saline a suitable candidate to provide protective and therapeutic effects in ORNJ. There are some articles related to bone metabolism improved by the use of hydrogen, but not many, so further research is required ${ }^{41,48,49} \mathrm{In}$ addition, hydrogen is regarded mainly as a preventive measure, and its therapeutic effect in established disease needs further study. We also believe hydrogen-rich saline could be used as an adjuvant therapy for ORNJ in conjunction with other methods, as it could delay the progress of the disease, reduce its severity, and increase the treatment effect, thereby improving patients' quality of life. Before hydrogen-rich saline can really become a promising novel therapy for ORNJ, a great many experiments both in vitro and in vivo need to be carried out to prove its effectiveness and feasibility. We also plan to perform an animal experiment to test this hypothesis (Figure 1). After effective animal experiments, multicenter clinical studies are also essential, and because the existing clinical research is limited, the optimal strategy for using hydrogen-rich saline must also be explored.

Although modern techniques of radiotherapy and radioprotection are increasingly used to reduce adverse effects, ORNJ still occurs, and there is very little progress in the development of effective therapies against it. However, this hypothesis provides us with a new idea. With advances in laboratory and clinical research, we believe that hydrogen-rich saline will provide greater hope for the prevention of ORNJ; it will also be beneficial in managing ORNJ, probably on the basis that ORNJ is a radiationinduced fibrotic disease believed to be associated with increased oxidative stress and inflammatory reactions; and that hydrogen can selectively reduce $\mathrm{OH}$ - and $\mathrm{ONOO}-$ radicals to exert its antioxidant activity, but does not affect physiological ROS. 


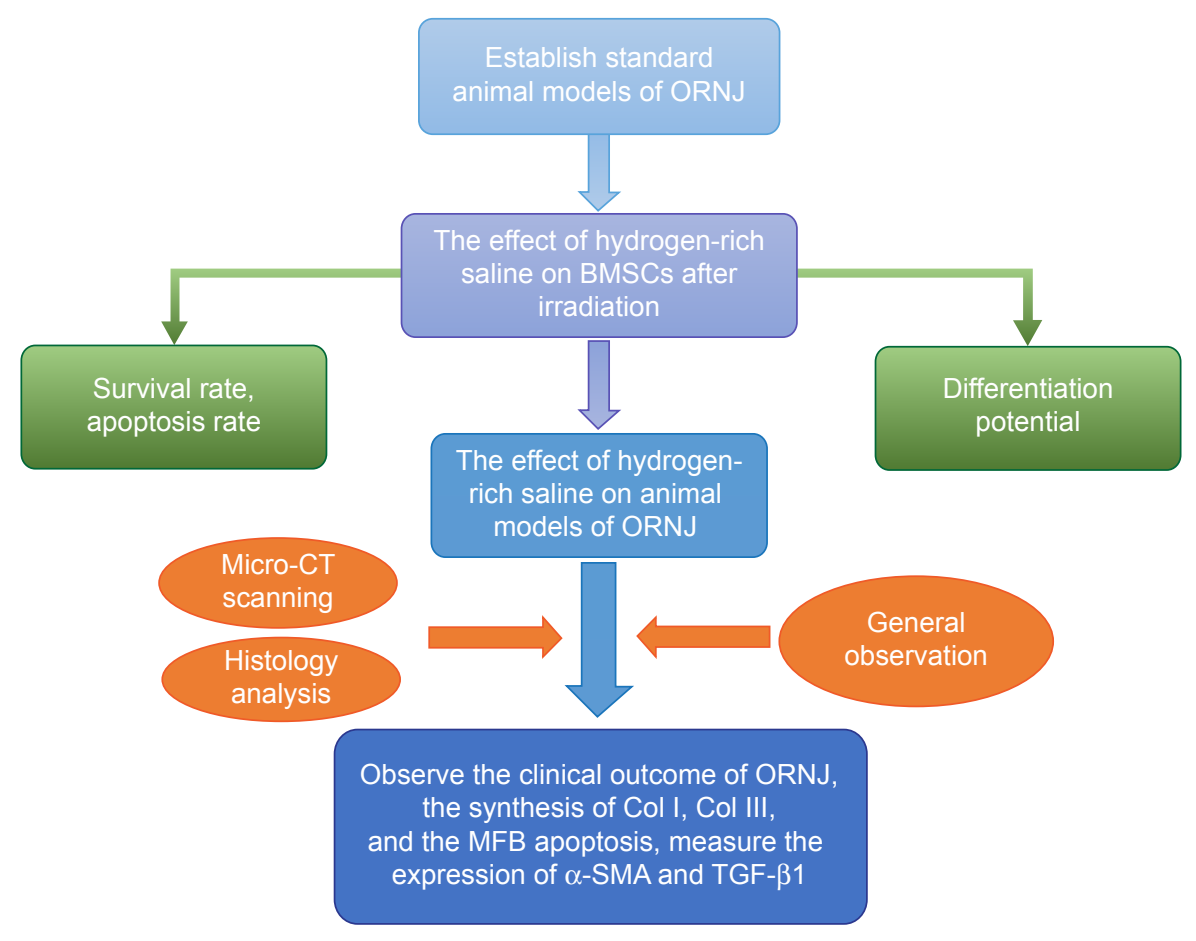

Figure I An experiment is designed for this hypothesis.

Abbreviations: ORNJ, osteoradionecrosis of the jaw; BMSCs, bone marrow mesenchymal stem cells; CT, computed tomography; MFB, myofibroblast.

\section{Acknowledgment}

This work was supported by funds from National Natural Science Foundation of China (81202150/H2201).

\section{Disclosure}

The authors report no conflicts of interest in this work.

\section{References}

1. Dixon BJ, Tang J, Zhang JH. The evolution of molecular hydrogen: a noteworthy potential therapy with clinical significance. Med Gas Res. 2013;31(1):10

2. Ohsawa I, Ishikawa M, Takahashi K, et al. Hydrogen acts as a therapeutic antioxidant by selectively reducing cytotoxic oxygen radicals. Nat Med. 2007;13(6):688-694.

3. Buchholz BM, Kaczorowski DJ, Sugimoto R, et al. Hydrogen inhalation ameliorates oxidative stress in transplantation induced intestinal graft injury. Am J Transplant. 2008;8(10):2015-2024.

4. Ji Q, Hui K, Zhang L, et al. The effect of hydrogen-rich saline on the brain of rats with transient ischemia. J Surg Res. 2011;168(1):e95-e101.

5. Fukuda K, Asoh S, Ishikawa M, et al. Inhalation of hydrogen gas suppresses hepatic injury caused by ischemia/reperfusion through reducing oxidative stress. Biochem Biophys Res Commun. 2007;361(3):670- 674.

6. Hayashida K, Sano M, Ohsawa I, et al. Inhalation of hydrogen gas reduces infarct size in the rat model of myocardial ischemia-reperfusion injury. Biochem Biophys Res Commun. 2008;373(1):30-35.

7. Zheng X, Mao Y, Cai J, et al. Hydrogen-rich saline protects against intestinal ischemia/reperfusion injury in rats. Free Radic Res. 2009;43(5): 478-484.

8. Chen H, Sun YP, Hu PF, et al. The effects of hydrogen-rich saline on the contractile and structural changes of intestine induced by ischemiareperfusion in rats. $J$ Surg Res. 2009;167(2):316-322.
9. Oharazawa H, Igarashi T, Yokota T, et al. Protection of the retina by rapid diffusion of hydrogen: administration of hydrogen-loaded eye drops in retinal ischemia-reperfusion injury. Invest Ophthalmol Vis Sci. 2010;51(1):487-492.

10. Shingu C, Koga H, Hagiwara S, et al. Hydrogen-rich saline solution attenuates renal ischemia-reperfusion injury. $J$ Anesth. 2010;24(4):569-574.

11. Fujita K, Seike T, Yutsudo N, et al. Hydrogen in drinking water reduces dopaminergic neuronal loss in the 1-methyl-4-phenyl-1, 2, 3, 6-tetrahydropyridine mouse model of Parkinson's disease. PLoS One. 2009;4(9):e7247.

12. Nagata K, Nakashima-Kamimura N, Mikami T, Ohsawa I, Ohta S. Consumption of molecular hydrogen prevents the stress-induced impairments in hippocampus-dependent learning tasks during chronic physical restraint in mice. Neuropsychopharmacology. 2009;34(2):501-508.

13. Liu Q, Shen WF, Sun HY, et al. Hydrogen-rich saline protects against liver injury in rats with obstructive jaundice. Liver Int. 2010;30(7): 958-968.

14. Chen H, Sun YP, Li Y, et al. Hydrogen-rich saline ameliorates the severity of L-arginine-induced acute pancreatitis in rats. Biochem Biophys Res Commun. 2010;393(2):308-313.

15. Ohsawa I, Nishimaki K, Yamagata K, Ishikawa M, Ohta S. Consumption of hydrogen water prevents atherosclerosis in apolipoprotein E knockout mice. Biochem Biophys Res Commun. 2008;377(4):1195-1198.

16. Nakao A, Toyoda Y, Sharma P, Evans M, Guthrie N. Effectiveness of hydrogen rich water on antioxidant status of subjects with potential metabolic syndrome-an open label pilot study. J Clin Biochem Nutr. 2010;46(2):140-149.

17. Regaud C. Sur la necrose des os attenté par un processus cancereux et traites par les radiaions[J]. Compt Rend Soc Biol. 1922;87(2):629-634. French.

18. Jereczek-Fossa BA, Orecchia R. Radiotherapy-induced mandibular bone complications. Cancer Treat Rev. 2002;28(1):65-74.

19. Madrid C, Abarca M, Bouferrache K. Osteoradionecrosis: an update. Oral Oncol. 2010;46(6):471-474. 
20. Chrcanovic BR, Reher P, Sousa AA, Harris M. Osteoradionecrosis of the jaws - a current overview - Part 1: physiopathology and risk and predisposing factors. Oral Maxillofac Surg. 2010;14(1):3-16.

21. Zhao W, Diz DI, Robbins ME. Oxidative damage pathways in relation to normal tissue injury. Br J Radiol. 2007;80 Spec No 1:S23-S31.

22. Brush J, Lipnick SL, Phillips T, et al. Molecular mechanisms of late normal tissue injury. Semin Radiat Oncol. 2007;17(2):121-130.

23. Vijayalaxmi, Reiter RJ, Tan DX, Herman TS, Thomas CR Jr. Melatonin as a radioprotective agent: a review. Int J Radiat Oncol Biol Phys. 2004; 59(3):639-653.

24. Halliwell B, Gutteridge JM. Free radicals, other reactive species and disease. In: Free radicals in biology and medicine. 3rd ed. London: Clarendon; 1999:246-350.

25. Stadtman ER. Oxidation of free amino acids and amino acid residues in proteins by radiolysis and by metal-catalyzed reactions. Annu Rev Biochem. 1993;62:797-821.

26. Fan X. Ionizing radiation induces formation of malondialdehyde, formaldehyde, and acetaldehyde from carbohydrates and organic acid. J Agric Food Chem. 2003;51(20):5946-5949.

27. Shirazi A, Ghobadi G, Ghazi-Khansari M. A radiobiological review on melatonin: a novel radioprotector. J Radiat Res. 2007;48(4):263-272.

28. Yan SX, Hong XY, Hu Y, Liao KH. Tempol, one of nitroxides, is a novel ultraviolet-A1 radiation protector for human dermal fibroblasts. J Dermatol Sci. 2005;37(3):137-143.

29. Delanian S, Lefaix JL. The radiation-induced fibroatrophic process: therapeutic perspective via the antioxidant pathway. Radiother Oncol. 2004;73(2):119-131.

30. Delanian S, Lefaix JL. Complete healing of severe osteoradionecrosis with treatment combining pentoxifylline, tocopherol and clodronate. Br J Radiol. 2002;75(893):467-469.

31. Chrcanovic BR, Reher P, Sousa AA, Harris M. Osteoradionecrosis of the jaws - a current overview - Part 2: dental management and therapeutic options for treatment. Oral Maxillofac Surg. 2010;14(2):81-95.

32. Cai J, Kang Z, Liu WW, et al. Hydrogen therapy reduces apoptosis in neonatal hypoxia-ischemia rat model. Neurosci Lett. 2008;441(2): $167-172$

33. Wood KC, Gladwin MT. The hydrogen highway to reperfusion therapy. Nat Med. 2007;13(6):673-674.

34. Sun H, Chen L, Zhou W. The protective role of hydrogen-rich Saline in experimental liver injury in mice. J Hepatol. 2011;54(3):471-480.

35. Sun XJ, Zhang JH. Hydrogen-an endogenous antioxidant in the body. Acad J Sec Mil Med Univ. 2008;29(3):233-235.

36. Wong JK, Wood RE, McLean M. Conservative management of osteoradionecrosis. Oral Surg Oral Med Oral Pathol Oral Radiol Endod. 1997; 84(1):16-21.
37. Reuther T, Schuster T, Mende U, Kubler A. Osteoradionecrosis of the jaws as a side effect of radiotherapy of head and neck tumour patients - a report of a thirty year retrospective review. Int J Oral Maxillofac Surg. 2003;32(3):289-295.

38. Epstein JB, Wong FL, Stevenson-Moore P. Osteoradionecrosis: clinical experience and a proposal for classification. JOral Maxillofac Surg. 1987; 45(2):104-110.

39. Dambrain R. The pathogenesis of osteoradionecrosis. Rev Stomatol Chir Maxillofac. 1992;94(3):140-147. French

40. Toussaint O, Dumont P, Dierick JF, et al. Stress-induced premature senescence: essence of life, evolution, stress, and aging. Ann N Y Acad Sci. 2000;908:85-98.

41. Qian L, Cao F, Cui J, et al. Radioprotective effect of hydrogen in cultured cells and mice. Free Radic Res. 2010;44(3):275-282.

42. Cai J, Kang Z, Liu K, et al. Neuroprotective effects of hydrogen saline in neonatal hypoxia-ischemia rat model. Brain Res. 2009;1256: $129-137$.

43. Sun Q, Kang Z, Cai J, et al. Hydrogen-rich saline protects myocardium against ischemia/reperfusion injury in rats. Exp Biol Med (Maywood). 2009;234(10):1212-1219.

44. Qian L, Cao F, Cui J, et al. The potential cardioprotective effects of hydrogen in irradiated mice. J Radiat Res. 2010;51(6):741-747.

45. Sato Y, Kajiyama S, Amano A, et al. Hydrogen-rich pure water prevents superoxide formation in brain slices of vitamin C-depleted SMP30/ GNL knockout mice. Biochem Biophys Res Commun. 2008;375(3): 346-350.

46. Kajiyama S, Hasegawa G, Asano M, et al. Supplementation of hydrogenrich water improves lipid and glucose metabolism in patients with type 2 diabetes or impaired glucose tolerance. Nutr Res. 2008;28(3): 137-143.

47. Cui Y, Zhang H, Ji M, et al. Hydrogen-rich saline attenuates neuronal ischemia-reperfusion injury by protecting mitochondrial function in rats. J Surg Res. 2014;192(2):564-572.

48. Qian L, Shen J, Chuai Y, Cai J. Hydrogen as a new class of radioprotective agent. Int J Biol Sci. 2013;9(9):887-894.

49. Yang Y, Gao F, Zhang H, et al. Molecular hydrogen protects human lymphocyte AHH-1 cells against $12 \mathrm{C} 6+$ heavy ion radiation. Int $J$ Radiat Biol. 2013;89(12):1003-1008.
Therapeutics and Clinical Risk Management

\section{Publish your work in this journal}

Therapeutics and Clinical Risk Management is an international, peerreviewed journal of clinical therapeutics and risk management, focusing on concise rapid reporting of clinical studies in all therapeutic areas, outcomes, safety, and programs for the effective, safe, and sustained use of medicines. This journal is indexed on PubMed Central, CAS,

\section{Dovepress}

EMBase, Scopus and the Elsevier Bibliographic databases. The manuscript management system is completely online and includes a very quick and fair peer-review system, which is all easy to use. Visit http://www.dovepress.com/testimonials.php to read real quotes from published authors. 